\title{
BUILDING A SUCCESSFUL CITY BRANDING CASE STUDY: DUBAI
}

\author{
Hesham Sameh ${ }^{1}$, Hosam Mohamed Abd El-Aziz ${ }^{2}$, Noha Hussein Hefnawy ${ }^{3}$ \\ ${ }^{1}$ Faculty of Engineering, Cairo University \\ ${ }^{2}$ Faculty of Engineering, Modern Academy for engineering and Technology \\ ${ }^{3}$ Faculty of Engineering, Benha University

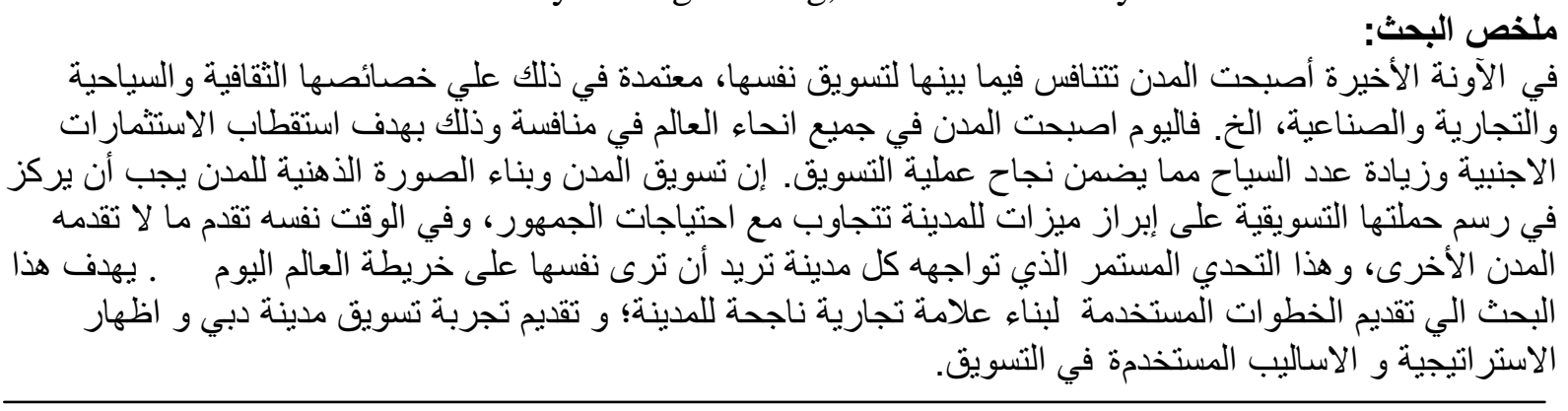

\section{ABSTRACT}

City branding is a current topic that is important nowadays. Many cities have actively started to build and manage their city brands during the last decades. Today, cities all over the world are competing with each other for different target markets and their attention. Cities aim to increase foreign direct investment and attract visitors, businesses, employees, talent, and residents with their city brand. This ensures the growth and success of branded places. In best cases, even small villages and locations are turned in to destinations with successful place marketing and branding efforts. The objective of this paper is to find out the steps of successful city branding process, and study the branding of Dubai.

Keywords: city branding, brand, place branding, brand identity, brand image.

\section{INTRODUCTION}

In recent years cities are in search for new ways to promote themselves. Due to fast changes in technology and the shift from local to a globalized environment, cities are forced to compete with each other in order to be an attractive tourist destination, workplace, cultural rich place and much more ${ }^{11}$. Worldwide competition between cities resulting from increasing economic and cultural globalization has been a stimulus for the development of place branding techniques. Cities all over the world need to express their unique characteristics, state their economic, cultural and political goals in order to differentiate themselves from other regions and better compete for resources, tourists and residents ${ }^{9}$. Moreover, branding of cities contribute to urban development and serve as a tool to improve the city positioning. Thus, city branding is a central activity within city management and one of the most debatable topics among place marketers. Its main objective is to launch new campaigns that would attract local population, tourists, and investors, in order to bring money to the city, improve its image worldwide and emphasize its distinctive identity. The city can develop multiple brands for different audiences; as City brand can serves as an umbrella covering all characteristics of city's life and activities. Generally, speaking, branding can be understood as generating 
expectations in actual and potential city users 'minds and ensuring that these expectations are met in the way people experience the city ${ }^{9}$.

The aim of this paper is to focus on finding the success factors of branding a city; in order to find out required organizational and managerial competences and best practices in successful city branding. This paper highlights the case study of Dubai and its branding process.

\section{LITERATURE REVIEW}

Place branding is an action of selecting all the positive factors of a place and then differentiating the place from others to promote its new image. When a place is branded, the name of a place brand is relatively fixed by the actual geographical name of the place ${ }^{3}$.

Place marketing means designing a place to satisfy the needs of its target markets. It succeeds when citizens and businesses are pleased with their communities, and the expectations of visitors and investors are met ${ }^{10}$. Place branding includes several different trends and forms of branding: nation branding, place of origin branding, destination branding, culture and entertainment branding and place and city branding. Place and city branding uses branding as an approach to integrate, guide and focus place management ${ }^{14}$.

The rising competition among cities might be seen as one of the effects of the globalization, which is visible in various forms and activity fields. The contemporary city has to be up dated continuously. In that sense cities develop strategies to support, to 'sell and advertise them within the global market. Literature survey reveals that there are mainly three approaches for promoting cities: cultural mega events, restoration and promoting heritage and the construction of iconic buildings. Among these approaches, construction of iconic buildings has been extensively utilized by many cities in order to get attention and attraction. The main motive behind this attempt is to create an identifiable image.

\subsection{Brand, and Branding}

A brand incorporates an entire set of physical and socio-psychological attributions and faiths associated with a product. It means more than the modulation of its precision: it means the creation of associations. "A brand is a product or a service realized distinctively by positioning it from the competition, its personality containing a unique combination of functional characteristics and symbolic values"8. So, the branding is a deliberate process of selection and corroboration of these qualities, because they can provide an added value to the basic product or service.

"A successful brand represents a product, a service, a person or a place traceable in a way in which the buyer or user finds relevant through the unique added value which best fits with his needs. Moreover, its success results from its capacity to sustain the added value against the competition",

Similarly, Kavaratzis\&Ashworth ${ }^{9}$ give a definition of a brand as _a product or service made distinctive by its positioning relative to the competition and by its personality, which comprises a unique combination of functional attributes and symbolic values ${ }^{6}$. According to the authors a brand is a complex construct through which managers attribute the value to the products or services. Additionally, branding makes it easier for consumers to recognize and appreciate these values. Branding is a mean of communication, where the central concept brand image endows perceptions of quality and values along with brand associations and feelings 9 . Summing up, branding is about making a difference by emphasizing unique attributes of a product. The intrinsic symbolic value is associated with social distinction or the emotional value the brand is communicating.

\subsection{Brand identity versus Brand image}

The crucial issue is the differentiation between brand identity and brand image. Brand identity involves a creation of a bond between the brand and the consumers, with a value proposition that consists of functional, emotional and self-expressed benefits ${ }^{9}$. The development of brand identity is an active process dependent on the company's strategy and vision, it represents how the company or a city wants to be perceived.

To compare with, brand image is the perception of a brand in the people's minds, it is what people think about the brand, their beliefs, expectations, emotions 9 . It is a passive process that takes places after the creation of an identity being peculiar evaluation of what was realized. 
It is important to say that the projected brand is not always consistent with brand image, the brand managers have no guarantee that the brand will be perceived in an expected way. The full coherence between identity and image is a very important issue, however difficult to achieve. Nonetheless, by developing a proper branding strategy, the company or location can minimize all the discrepancies between the two. Nowadays, it can be noticed that some city brands are more successful than others. One of the greatest examples of the very positive results in branding the city is New York. After a success of _I love NY' branding campaign, the city launched _New York work' which appeared to reflect the city's dynamism and _can do attitude, by portraying the city as a perfect place to work and prosper ${ }^{11}$. As a result of the creation of a clear identity the city is regarded as it aspired to be perceived.

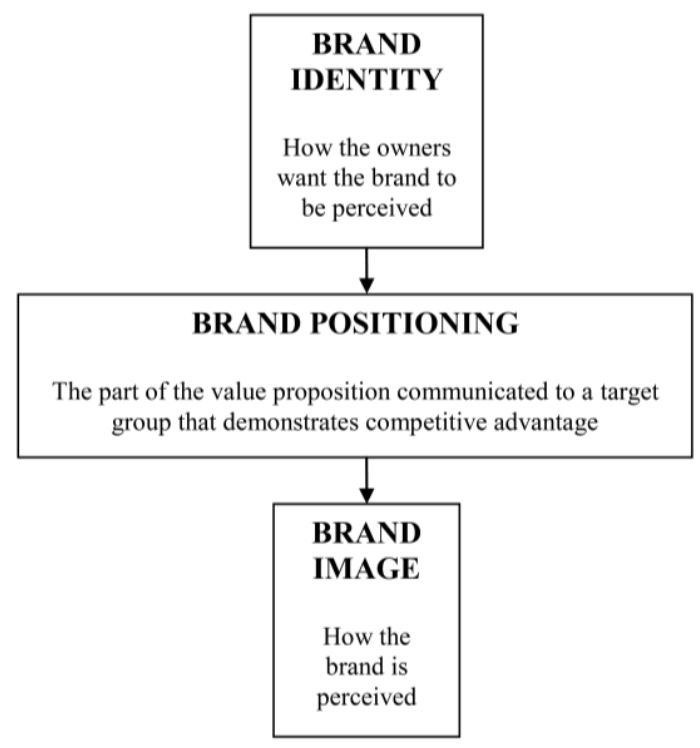

Fig. 1 Brand components Source: Kavaratzis \& Ashworth (2005)0

\subsection{City Branding Importance and Definitions}

There are many reasons why it is critical for a city to be branded, but the most common is to stimulate economic growth. That's because a strong brand can $^{4}$ : shift the perception of a city that may be suffering from a poor image among external and internal constituents, create a common vision for the future of the community and its potential, provide a consistent representation of the city, enhance its local, regional and/or global awareness and position, shed unfavorable stereotypes associated with a city and make it more appealing.

Place branding aims to link place identity and perceived images through memorable place experiences and projected images. It is an idea of bridging the gap between reality and perception using experience and communication.

City branding developed as a part of city marketing which is an integral part of place management and urban planning. The goal of city marketing is to attract and mobilize the factors of external growth such as purchasing power, investments and public support funds, production potential and innovation ${ }^{12}$. City branding is a broader concept then city marketing as it focuses on a holistic vision and cohesion between brand identity and image, whereas city marketing is mainly related to fulfilling customers' needs and expectations.

City branding concept can be defined as "the practice of developing a strategy that underlines the value the place offers to its target publics, namely residents, workers, employers, investors, tourists and so on",2.

A city brand is "its promise of value, a promise that needs to be kept. In branding the city, that 'value' is created, developed and demonstrated through different kinds of actions such as investments, physical and economic plans, attraction programs, events and communications", 


\section{HOW TO BRAND A CITY}

A city needs to be known and positioned on the global map of attractive cities to attract inhabitants, investors, businesses and tourists. There are some essential Steps that help in the creation of a successful city brand

A city can follow an eight-step process to develop a place brand ${ }^{4}$ :

Step 1: Define clear objectives; it is imperative that decision makers understand the goals and objectives of the branding initiative. Is the primary objective to attract and retain residents? Drive commerce? Attract visitors? Change current perceptions? The answers to these questions (and the priorities among them) help define the scope of the project, the appropriate stakeholders with whom to speak and the key activities that form the approach to the initiative.

Step 2: Understand the audiences you are trying to attract; selecting the right target audiences is one of the most difficult steps in place branding. It is tempting to want to talk to everyone. As with overall project scope, audiences need to be minimized in number and prioritized based on importance.

Step 3: Identify current brand image of the place; the ultimate goal is to understand how the target audience perceives the place today so that the gap between the current state and the desired or aspirational state can be assessed. It is this gap that the positioning must close.

Step 4: Set the aspirational identity for the place; an aspirational brand identity consists of the associations you want people in the future to make when they think of your community. It is how you want target audiences to view the brand and the benefits they expect to receive from it. It should influence future business and community decisions.

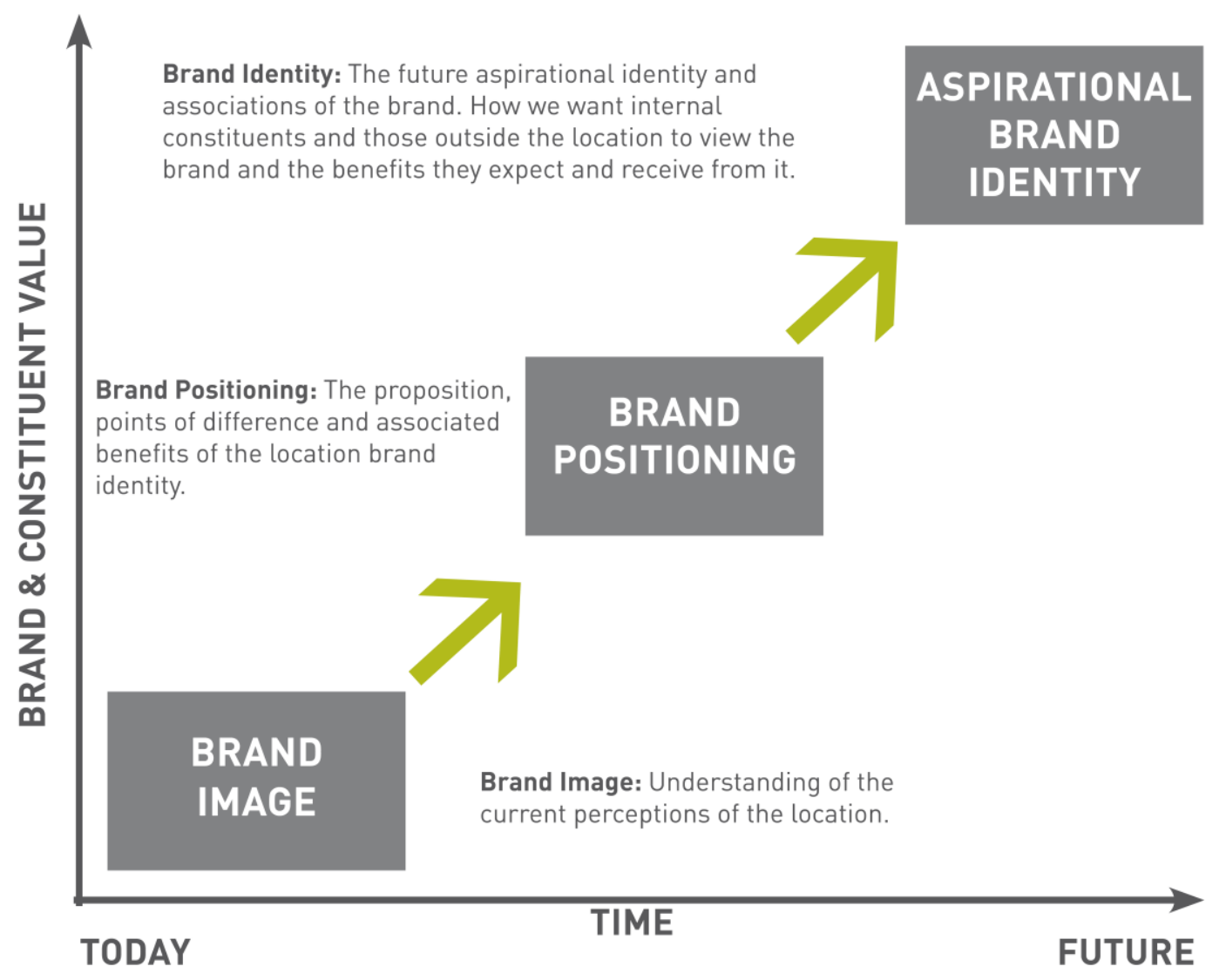

Fig. 2 moving from brand image to brand identity Source: CEOs, (2006)

Step 5: Develop the positioning; Brand positioning is the means for transitioning from a place's current brand image to its aspirational identity. Essentially, the positioning is a promise or a benefit that a place wants to own in the minds of the target audience.

Step 6: Create value propositions for priority target segments; once the positioning is defined, it is important to make it actionable for each of the target audiences. Specifically, what does the positioning mean for that audience and what are the key messages that should 
be communicated to influence their perceptions? There are some messages that will be applicable to all audiences. But it is also important to get specific on the detailed messages that are important to each individual audience. This process makes the strategy more tangible and helps various organizations deliver a cohesive story.

Step 7: Execute the strategy; in developing your brand-based marketing plan, it is critical to think about every point at which the target audience may come into contact with your brand. Every interaction or point of contact with the target audience is an opportunity either to enhance or denigrate your brand. These points of contact, or touch points, may include a wide spectrum of elements such as the physical environment, the airport, street signage, advertising, brochures, web site, events, media and even the attitude of residents.

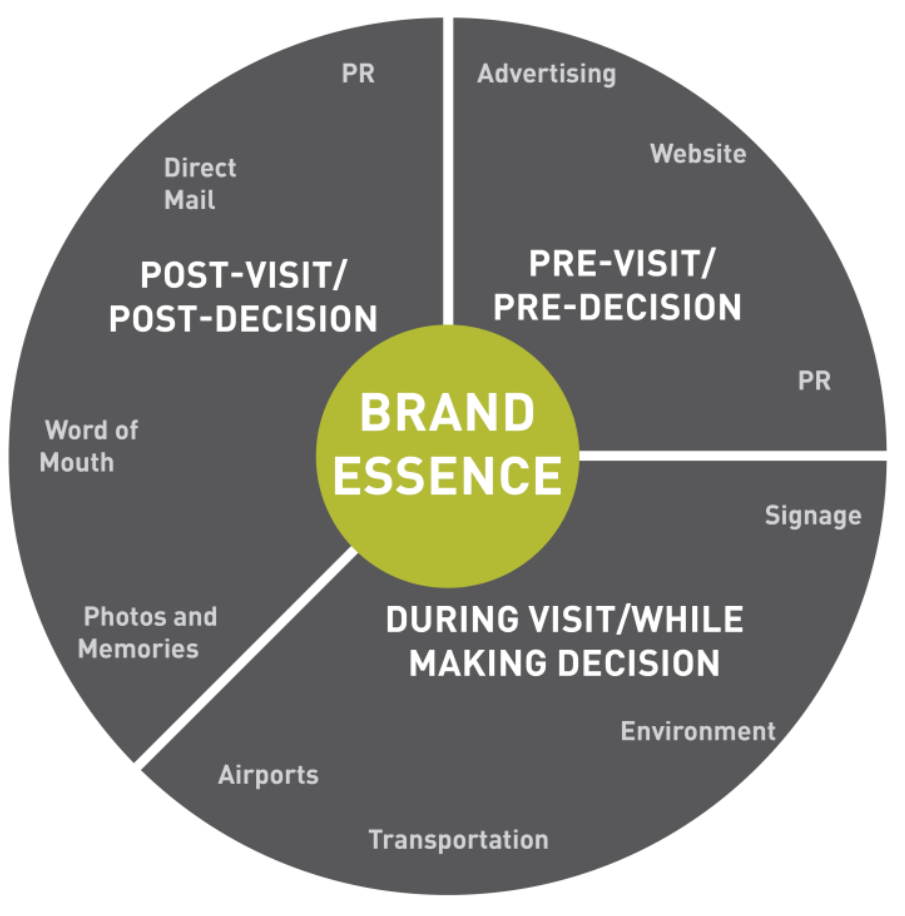

Fig. 3 Touch points to deliver on the brand Source: CEOs, (2006)

Step 8: Measure success; The adage, "What is not measured is not managed," is true for all branding, whether product, service or place. The link between business and brand strategy becomes evident as return on investment and the positive economic, social and political impacts are measured over time.

\section{CASE STUDY: DUBAI}

Dubai is located in the Middle East and is one of the seven emirates of the United Arab Emirates. It is the second biggest emirate and is situated at the banks of Dubai Creek, which is a natural inlet of the Persian Gulf.

\subsection{Economic and Political Situation}

Currently Dubai has a very diverse and dynamic economy, and is one of the largest reexporter of goods in the Middle East. Investors from all over the world are being attracted to the low logistical and operational costs, infrastructure, and liberal government policies that Dubai offers. Major industries such as trade, transport, tourism, and finance have been on a constant growth. Dubai is politically headed by a hereditary ruler, which comprises the UAE's Supreme Council of Rules, which is headed by a President.

Dubai's economy is able to compete on several factors such as cost, market, and the environment. These combined factors are able to create an advantage for Dubai to compete on the world market as an attractive city for local and foreign investors.

Low crime rates, well-developed and sophisticated banking system "features extensive credit facilities and ample liquidity". The government is committed to seeing business thrive in city, and employs liberal economic policies. In addition, there are clear ownership laws and 
regulations in place, which provide foreigners with ownerships rights of up to " $49 \%$ for limited liability companies established within the Emirate of Dubai and up to $100 \%$ for professional companies, branches and representative offices of foreign companies and free zones enterprise." 13 .

\subsection{Tourism}

Dubai prides itself on its tourism, as it claims that hospitality has been their tradition for centuries. The government's main strategy is "to position Dubai as the leading tourism destination and commercial hub in the world and to strengthen the Dubai economy". Dubai is quite diverse, and hence there are many attractions that tourist can see, and many activities they can partake in. There are many natural and historic sites, such as the desert and sand dunes, mountains, parks and ancient houses - to quite an opposite experience, of modern architectural marvels, luxurious buildings and enormous shopping malls.

In addition to being a multi-faceted city, and offering facilities "of the highest international standards combined with the charm and adventure of Arabia", Dubai provides a friendly, safe and basically crime-free environment for tourists. According to the Dubai Department of Tourism and Commerce Marketing, there are five key ingredients that have "earned Dubai a growing reputation as one of the world's most attractive and rapidly developing leisure destinations" - and those are sunshine, shopping, seaside, sports, and safety. Dubai is also established itself as the trading and commercial hub of the Middle East. All of these factors placed together result in a new and different tourist destination "combining the traditions of the East with the comforts of the West" and this is how the city Dubai is marketing itself to the rest of the world.

\subsection{Branding Dubai}

Dubai developed a strategic vision for the years 2010 and 2020; to raise the number of the tourists visiting Dubai in order to reduce the country dependency on the oil as a source of revenue.

The branding vision of Dubai municipality is to promote the city as an excellent city that provides the essence of success and comfort living, as well as a leading commercial, residential, exhibition and convention center in the Middle East and adjacent regions.

\subsubsection{Brand Identity}

Dubai has positioned itself as a home of luxury in various aspects. With being the most liberal out of the 7 emirates where many cultures meet, the city views itself as a melting pot that creates a unique atmosphere. The city strives to become a, what they call a 'global Arabic city' with a strong grounding in its heritage ${ }^{1}$.

In Dubai, many slogans are used to promote the area; however the slogan that the Dubai Department of Tourism and Commerce Marketing use is "Nowhere like Dubai". The brand identity that was launched on May 5, 2009 includes the tagline 'Definitely Dubai' and the following brand signature ${ }^{14}$.

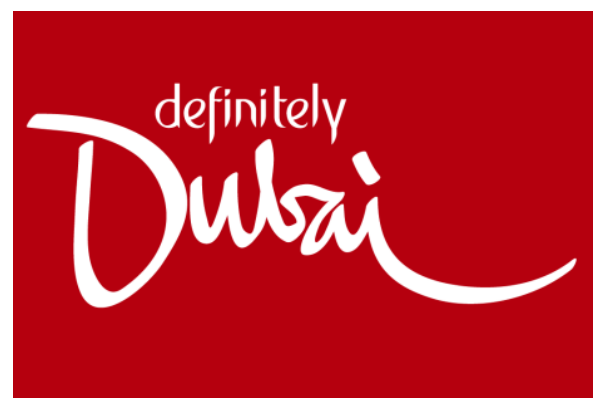

Fig. 4 New Brand Dubai Signature

Source: https://skift.com/wp-content/uploads/2013/11/mzl.hbdqgnvv.png, accessed (10-2-2018)0

\subsubsection{Target Group}

Residents: many of Dubai residents are overseas; it is expected that the city will receive more expatriates within the forth coming years.

Visitors: the visitors and tourists of Dubai expect to get an environment for all outdoor activities, such as sports and entertainment, a huge variety of fashionable places and events. 
Inventors: Dubai becomes the home of the largest deals and developments projects.

\subsubsection{Branding strategies}

Dubai represents itself as a city of contrast, from the architecture through its diversity of culture and people who come to Dubai from every continent. This makes it one of the most cosmopolitan cities in the world and an attractive tourism and lifestyle destination.

The city offers many attraction and lifestyle activities to its visitors to enjoy, like the wide variety of the shopping malls, Dubai Land, the Global Village, traditional markets, urban parks, and heritage sites.

The city also hosts numerous trade exhibitions and conventions throughout the year. The Dubai World Trade Center and the Airport Expo Center host many of the region's largest and most prestigious exhibitions.

Promoting of new urban projects is frequently increasing in Dubai. The effectiveness of the new project is explained by their approach towards superlatives; where the tallest, the biggest, the largest, etc.; which seems to be necessary adjectives for the urban projects to attract inventors, and visitors.

Dubai also became an attractive destination for many international prominent architects to design and build their landmarks and buildings; like the recent work of Zaha Hadid (The Opera and Museum Dubai, The Dancing Dream Towers, and OPUS towers). The skyscrapers designed by the international architect are few examples of this trend. For Dubai, architecture has an important role in branding the city through the creation of new icons, landmarks, or wonders to discover new unique and distinct architectural images that can be better promoted and sold.

\section{CONCLUSIONS AND RECOMMENDATIONS}

The research study reached the following conclusions and recommendations:

\subsection{Conclusions}

There is a strong link between a city's identity and its brand. A city brand should encompass the city's core values, characteristics and aspirations. The brand message points to a future perspective, while at the same time being rooted in the true story of the city. In conclusion, without a clear, distinctive identity and vision, even the best cities won't be able to achieve desirable image and the brand will have seemingly failed.

As the analysis shows, Dubai portrays itself as a luxurious vacation destination, which is congruent with what the city actually offers. Therefore, it can be concluded that the designed brand identity matches what the city has to offer. Additionally, the recently launched brand identity also matches what the city offers, to a certain extent. In terms of the brand image, it seems that people have a clear mental picture of what Dubai offers, even if they have not previously visited the city. Overall, the perceptions are rather positive and match what the city is about.

\subsection{Recommendations}

Enforcing and extensive promotion of the brand identity is crucial during the early stages of city branding process. It is important to create awareness and inform the global audience of city's offerings.

Monitoring and follow-up of the brand should be done in the near future and on a regular basis to ensure the successfulness of the branding efforts. This will also help to find out if any adjustments need to be made to create a positive brand image of cities

\section{FURTHER RESEARCH}

As the branding of a city is complex, future research could be done to further understand city branding and to be able to highlight certain success factors. This could be done by extending the list of investigated cities by looking at further cities around the world, varying in size and offerings. Additionally, a larger sample size could be used to gain deeper insight of how the global audience perceives each city to be. This would then need to be compared to how each city brands itself, whether there is a match and lastly if certain aspects can be filtered out of each city's branding process that can lead to successful brand identity. 


\section{REFERENCES}

1. Balakrishnan, M.S., (2008). Dubai - a star in the east. Journal of Place Management and Development. Vol. 1 No. 1, 2008 Retrieved April 4, 2009 from Emerald database.

2. Biçakçi, A., (2012), Branding the city through culture: Istanbul, European Capital of Culture, 2010, Vol.9, issue 1, International Journal of Human Sciences.

3. Cai, L. P. (2002). Cooperative branding for rural destination. Annals Tourism Research, Vol. 29, No. 3, pp. 720-742.

4. $\quad$ CEOs for Cities | March 2006. Branding. Your City, ceosforcities.org.

5. De Chernatory, L. \& Dall'Olmo Riley, F. 1998. Defining a "brand": beyond the literature with experts' interpretations. Journal of Marketing Management, Vol.14, pp. 417-443.

6. Gelder, S., and Allan, M., (2006), City Branding: How Cities Compete in the 21st Century, UK, Primaveraquint.

7. Govers, R. \& Go, F. (2009). Place Branding;Glocal Virtual and Physical Identities; Constructed, Imagined and Experienced. Hampshire, England: Palgrave Macmillan.

8. Hankinson, G. 2004. Relational network brands: towards a conceptual model of place brands. Journal of Vacation Marketing, Vol. 10, No. 2, pp. 109-121.

9. Kavaratzis, M. \& Ashworth, G., (2005), City branding: An effective assertion of identity or a transitory marketing trick?, Tijdschrift voor Economische en Sociale Geografie 2005, Vol. 96, No. 5, pp. 506-514.

10. Kotler, P., Asplund, C., Rein, I. \& Haider, D. 1999. Marketing places Europe: attracting investments, industries, residents and visitors to European cities, communities, re-gions and nations. Pearson Education Limited. London.

11. Kotler, P., Gertner, D. (2002), "Country as a brand, product and beyond: A place marketing and brand management perspective", Journal of Brand Management, Vol. 9 (4/5), pp. $249-261$.

12. Krantz, M \& Schatzl, L. Marketing the City. In: European Cities in Competition (eds), Jensen- Butler,C., Shachar, A., Weesep, J. (eds) 1997. Avebury: Ashgate Publishing Company.

13. Salman, S., (2008), Brand gold, https://www.theguardian.com/society/2008/oct/01/city.urban.branding, accessed (10-2-2018).

14. Schneider, E., Korelin, K., (2009), City Branding - A comprehensive outlook of four international cities, International Marketing Master's Program.

15. Warnaby, G. 2009. Towards a service-dominant place marketing logic. Marketing Theory, Vol. 9, No. 4, pp. 403-423. 